\title{
latrogenic Invasion of Maxillary Sinus in Oral Surgery
}

\author{
Antonio Crispino, Leonzio Fortunato, Luigi Lidonnici, Roberto Del Giudice \\ Department of Dentistry, University of Catanzaro "Magna Graecia”, Catanzaro, Italy \\ Email address: \\ crispino@unicz.it (A. Crispino), leo@unicz.it (L. Fortunato), odonto.lidonnici@gmail.com (L. Lidonnici), \\ robter1@hotmail.it (R. Del Giudice)
}

\section{To cite this article:}

Antonio Crispino, Leonzio Fortunato, Luigi Lidonnici, Roberto Del Giudice. Iatrogenic Invasion of Maxillary Sinus in Oral Surgery. American Journal of Clinical and Experimental Medicine. Vol. 3, No. 6, 2015, pp. 383-385. doi: 10.11648/j.ajcem.20150306.21

\begin{abstract}
Iatrogenic diseases affecting the maxillary sinus may be consequent to both technical errors operator both represent something "inevitable", linked to the particular situation of anatomical contiguity between pathologic finding to be removed and the sinus. They can result from multiple occurrences: Extraction of dental elements erupted of the posterior maxilla, most frequently in the case of multi-rooted elements with roots long and diverse; Surgical extraction of impacted teeth, especially the third molars, second premolars and, more rarely, canines; Dislocation in the roots of the maxillary sinus, dental elements or parts of fractured instruments (in this case the event is always tied to a technical error); Enucleation of periapical lesions or cysts whose walls are adherent to the sinus mucosa; Removal of benign growths such as odontomas or other odontogenic tumors and odontogenic not directly related to the sinus mucosa; Preparation of implant sites in the posterior maxilla, due to incorrect assessment of the space available between the alveolar margin and sinus floor. Meta-analytical, observational and retrospective study obtained from a literature review of 10 articles. Its primary etiological factor is dental extraction and preparation of dental implant sites. The lesions iatrogenic sinus occurred during oral surgery or implant surgery can be provided and certainly reduced. The way forward is that of a careful planning designed to reduce the risk of accidents during surgery.
\end{abstract}

Keywords: Maxillary Sinus, Oral Surgery, Dental Implant

\section{Introduction}

Among all the lesions, communications-antrum represent the most frequent occurrence, and are characterized by the presence of an interface between the oral cavity and the maxillary sinus without an epithelial lining of the latter and represent the initial phase of the disease process and are still susceptible spontaneous healing.

Fistulas-antrum are represented instead by a through covered by epithelium, which originates from the oral mucosa and / or the sinus mucosa, and which prevents the spontaneous healing and represent the most advanced stage of the disease process [1].

The pseudopolyps sinus formed after the eversion of the sinus mucosa through communication and typically occur after very large communications be accompanied by a chronic infection of the cave.

The fistula is established for migration of oral communication, event that occurs when the drilling has lasted for at least 48-72 hours. Histological examination through appears covered with cylindrical ciliated epithelial tissue and there is a fibrous layer consists of collagen fibrils and rare fibrocytes. Such fabrics are disposed concentrically to one another [2].

The establishment of the via is in turn an element that prevents the restoration of a situation of balance in the oral cavity because of the frequent sinusitis that are to occur, the processes of erosion of the bone tissue adjacent and oral infections.

The mouth-antrum not surgically treated may have different developments, which are determined both by the dimensions of communication both by the degree of secondary infection of the maxillary sinus. As general rule, communications traumatic in origin, and of small size (less than $5 \mathrm{~mm}$ ) also can settle spontaneously following the Primary organization of the clot that forms after the traumatic event (iatrogenic or otherwise).

In the case of communications broader the probability of spontaneous healing decreases, while it increases the possibility of infection of the sinus due to a contamination by the microbial flora intraoral, with the risk of a framework genuine of sinusitis [3].

When pathogenic germs colonize the maxillary sinuses establishing an inflammatory process, the limited or no 
drainage and the small size of the cavity, further reduced by phenomena of edema, constitute the anatomic substrate for the maintenance and then the chronicity of the inflammation sinus. In fact, the pathogenesis of chronic sinus inflammation lies in their insufficient ventilation and poor drainage [4].

\section{Clinical Examination}

The operations to be carried out to diagnose a lesion interesting the maxillary sinus following the rules of classical semiotics.

In the case of a simple communication gold-sinus inspection a lesion regions can not be immediately visible, as opposed to a broad one. The use of a dental mirror can be of help as well as the survey through a simple periodontal probe.

Placing a suction cannula in correspondence with the communication can be felt a thud and amplified given by the air flow created within the maxillary sinus, which acts as a resonance box [5].

The irrigation of the operative site at the end of intervention is perceived by the patient with the passage of the liquid towards the nose.

The Valsalva maneuver, causing an increase in air pressure endosinusale, in case of communication is manifested in the form of bubbles at the level of the continuous solution between the oral cavity and sinus. More rarely it highlights the material coming out of the nose blood.

In the case of a fistula oroantral now instauratasi by time, the lesion presents two clinical pictures: the first characterized by an orifice from which you can highlight or less material spillage serous or purulent; the second, especially in cases of greater size, characterized by the presence of a herniation of polypoid aspect of the mucosa of the maxillary sinus, who may be accompanied by the leakage of purulent material [6].

In the absence of full-blown sinus infection, extra-oral examination does not detect anything abnormal. Only in case of sinusitis may appear swelling of the paranasal and / or cheek often associated with pain and redness.

\subsection{Symptomatology}

The orosinusal communications have symptoms very variable, in relation to the duration of the process and the size of the communication. Symptoms may be immediate or may occur after some time of the injury. Typical symptoms consist in the feeling of the passage of air or liquid between oral and nasal cavities. Usually the pain is absent unless there is acute inflammatory diseases of the mucosa of the sinus. In this case the pain can be exacerbated by palpation of the anterior wall of the womb. The patient may also report a sense of tension in the region of the sinus, with possible radiation to the orbit, or sense of elongation or tension of teeth whose roots are related to the sinus [7].

Acute maxillary sinusitis of dental origin have persistent pain symptoms to the emiface concerned, malaise and mild temperature, pain on palpation of the regions suborbital and canine fossa [8]. In a course of time the pain subsides as it appears purulent nasal whose amount varies depending on the position of the patient's head.

Chronic sinusitis, whose most common form is that of dental origin, of presents from the clinical point of view with the triad: purulent discharge, subjective bad semel and pain [9]. The secretion is unilateral with pus-looking greenish-yellow and it is prolonged abnormally over time often mingling with the evolution of a common cold. The bad smell, frequent in the forms clearly odontogenous, perceived only by the patient, acquires relevance value in the absence of purulent sinusitis in cases of so-called blocked. The pain finally may occur in varying degrees, by vague soreness widespread, easily bearable, in real pain crisis to be considered related to episodes of retention of pus or exacerbation of chronic process [10].

\subsection{Radiology}

Radiologically communication appears as a discontinuity of the floor antrum, accompanied by a lower radiolucency of this when there is an inflammatory reaction of the mucosa or a collection purulent. Only the X-ray examination, performed with the aid of such a probe or a gutta-percha cone introduced in the notice or fistula, it shows with certainty the presence of the lesion [11]. Sometimes communications are complicated by the dislocation within the maxillary sinus or dental root fragments of broken instruments after surgical procedures incorrect. In such situations, the inflammation of the sinus mucosa is more likely to occur, which can lead to a full-blown picture of maxillary sinusitis.

The radiograph is the preferred technique for communications postestrattive but offers a limited field.

An overview can be better provided by the panoramic x-ray but, for a detailed and three-dimensional computed tomography is the ideal tool, especially in complex cases with sinus infection, as it shows clearly the perimeter of the fistula and its relationship with the adjacent anatomical structures.

\section{Conclusion}

As our results show, what is certain is that it appears evident that in the literature reviewed that, in most cases, the lesions iatrogenic sinus occurred during oral surgery or implant surgery can be provided and certainly reduced. The way forward is that of a careful planning designed to reduce the risk of accidents during surgery. Certainly the radiological investigations and careful preparation for surgical intervention complement the possibility to reduce the risk of such injuries that can lead to a worsening of the health condition of the patient. 
Table 1. Studies on the treatment and complications of OAC [12].

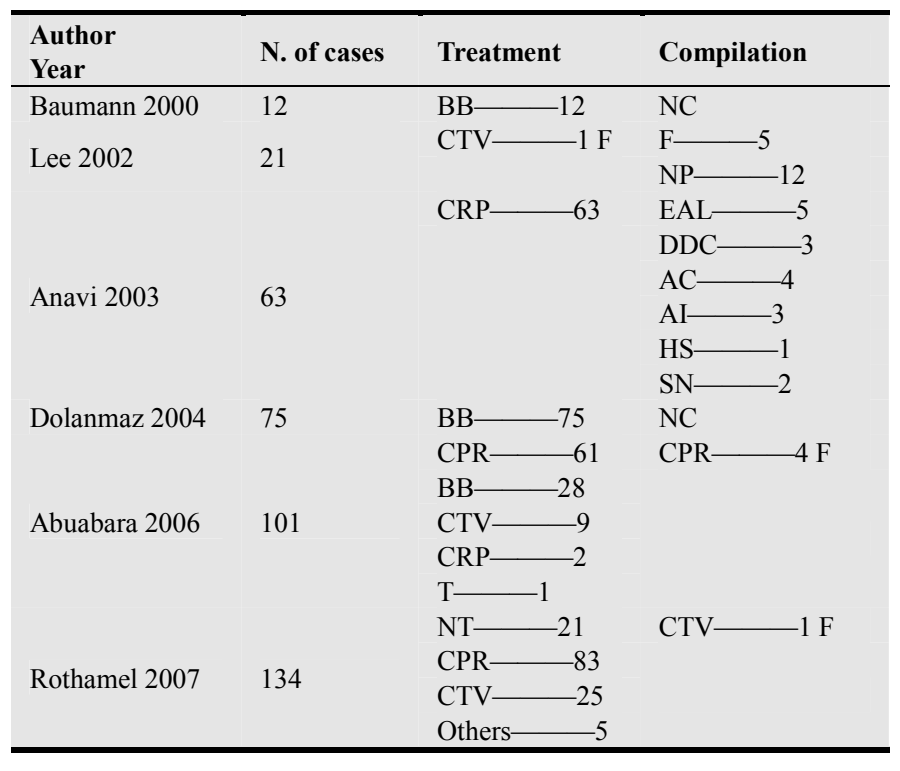

\section{References}

[1] Ahovuo-Saloranta A, Rautakorpi UM, Borisenko OV, Liira H, Williams JW Jr, Mäkelä M. WITHDRAWN: Antibiotics for acute maxillary sinusitis in adults. Cochrane Database Syst Rev. 2015 Oct 16; 10: CD000243.

[2] Saibene AM, Vassena C, Pipolo C, Trimboli M, De Vecchi E, Felisati G, Drago L. Odontogenic and rhinogenic chronic sinusitis: a modern microbiological comparison. Int Forum Allergy Rhinol. 2015 Sep 8. doi: 10.1002/alr.21629.

[3] Troeltzsch M, Pache C, Troeltzsch M, Kaeppler G, Ehrenfeld M, Otto S, Probst F. Etiology and clinical characteristics of symptomatic unilateral maxillary sinusitis: A review of 174 cases. J Craniomaxillofac Surg. 2015 Oct; 43(8): 1522-9. doi: 10.1016/j.jcms.2015.07.021.
[4] Guerra-Pereira I, Vaz P, Faria-Almeida R, Braga AC, Felino A. CT maxillary sinus evaluation--A retrospective cohort study. Med Oral Patol Oral Cir Bucal. 2015 Jul 1; 20(4): e419-26.

[5] Yan J, Zhao Y. [The research progress of maxillary sinusitis surgery]. Lin Chung Er Bi Yan Hou Tou Jing Wai Ke Za Zhi. 2015 Feb; 29(3): 287-90.

[6] Ference EH, Smith SS, Conley D, Chandra RK. Surgical anatomy and variations of the infraorbital nerve. Laryngoscope. 2015 Jun; 125(6): 1296-300. doi: 10.1002/lary. 25089.

[7] Tomomatsu N, Uzawa N, Aragaki T, Harada K. Aperture width of the osteomeatal complex as a predictor of successful treatment of odontogenic maxillary sinusitis. Int $\mathrm{J}$ Oral Maxillofac Surg. 2014 Nov; 43(11): 1386-90. doi: 10.1016/j. ijom. 2014.06.007.

[8] Hu Z, Sun D, Zhou Q, Wang Y, Gu J, Han Y. [Radiographic study of maxillary sinus associated with molars in adult]. Lin Chung Er Bi Yan Hou Tou Jing Wai Ke Za Zhi. 2014 Dec; 28(23): 1863-5.

[9] Saibene AM, Vassena C, Pipolo C, Trimboli M, De Vecchi E, Felisati G, Drago L. Odontogenic and rhinogenic chronic sinusitis: a modern microbiological comparison. Int Forum Allergy Rhinol. 2015 Sep 8.

[10] Feng L, Li H, E LL, Li CJ, Ding Y. Pathological changes in the maxillary sinus mucosae of patients with recurrent odontogenic maxillary sinusitis. Pak J Med Sci. 2014 Sep; 30(5): 972-5.

[11] Franco-Carr o B1, Barona-Dorado C, Martínez-González MJ, Rubio-Alonso LJ, Martínez-González JM. Meta-analytic study on the frequency and treatment of oral antral communications. Med Oral Patol Oral Cir Bucal. 2011 Aug 1; 16(5): e682-7.

[12] Franco-Carro B, Barona-Dorado C, Martínez-González MJ, Rubio-Alon- so LJ, Martínez-González JM. Meta-analytic study on the frequency and treatment of oral antral communications. Med Oral Patol Oral Cir Bucal. 2011 Aug 1; 16 (5): e682-7. 